\title{
The Sower's Way: A Strategy to Attain the Energy Transition
}

\author{
Ugo Bardi ${ }^{1 *}$, Ilaria Perissi ${ }^{2}$, Denes Csala ${ }^{3}$ and Sgouris Sgouridis ${ }^{3}$ \\ ${ }^{* 1}$ Dipartimento di Scienze della Terra, Università di Firenze, Italy \\ ${ }^{2}$ Consorzio Interuniversitario di Scienza e Tecnologia dei Materiali, INSTM, Firenze, Italy \\ ${ }^{3}$ Engineering Systems and Management, Masdar Institute, Abu Dhabi, UAE \\ Email: ugo.bardi@unifi.it
}

\begin{abstract}
In order to face resource depletion and climate change, society needs to move as quickly as possible to a renewable energy supply. Here, we argue that the transition can be seen as a process similar to the challenge faced by ancient farmers who had to save some of their harvest as seed for the next harvest. In the present case, during the initial phase of the transition, we need to save and invest part of the energy produced by fossil fuels in order to build their own replacement in the form of renewable energy plants. This strategy is called here "the Sower's Way". The needs for the transition can be quantified in terms of the "energy return for energy invested" (EROI or EROEI) in order to estimate the amount of "seed" that's necessary to invest before either fossil fuels become too expensive to be profitably extracted or the temperature rise caused by greenhouse gases exceed the safe limits, as they are understood today. Taking into account that it is necessary to maintain a minimum level of energy supply for a growing human population and for improving the living standards of people living in poor countries, the calculations indicate that a considerable increase in the investments in renewable energy is necessary, and that it is necessary to start as soon as possible.
\end{abstract}

Keywords: Energy transition, Sower's way, Renewable energy, EROI.

\section{INTRODUCTION}

"Don't eat your seed corn!" is a well known saying. It refers to the age-old farmer's strategy of saving some of the harvest of the current year as seeds for the next. Unfortunately, however, our main energy source today, fossil fuels, produce no "seeds." Once extracted and used, fossil carbon compounds are gone forever in the form of the gaseous products of burning them, mainly carbon dioxide $\left(\mathrm{CO}_{2}\right)$. So far, we have been behaving like farmers who eat their seed corn; consuming fossil fuels as fast as possible, without placing much thought to the future. And we are still expending enormous amounts of money and resources just to continue doing that. This is the result of our current way of thinking which emphasizes short term gains at the expenses of long term costs. This way of thinking creates enormous problems: first and foremost, that of climate change, but also that of the gradual depletion of fossil will force us to reduce the flow of energy to the world's economy before we have an alternative source.

An alternative strategy calls for creating a new energy infrastructure based on renewable energy in the form of either direct solar light or indirect forms, such as wind, hydropower, but also geothermal and tidal. This new infrastructure includes not only energy producing plants, but also the capability of using this energy to provide the essential services for the industrial society: communication, transportation, manufacturing, agriculture, and more. The new infrastructure can be, and must be, more efficient than the old one in the sense of providing the same services at lower energy costs. Nevertheless, attaining higher efficiency also requires investments and, hence, energy. The energy invested for the new infrastructure will not be available for consumption and, therefore, implies a certain degree of sacrifice for the members of society.

In the future, the renewable energy infrastructure will have to provide sufficient energy for its replacement; that is, it will provide sufficient "seed" to renew itself. At present, however, most of the energy supply for the industrial society comes from fossil fuels, which are the only possible source able to provide the initial "seed" for the new infrastructure. Allocating a appropriate amounts of energy for attaining the energy transition is called here the "Sower's way" [1], the same strategy that ancient farmers used by saving part of their current harvest as seed for the new one. The question is whether it is possible to allocate a sufficient amount of energy for this transition, according to three fundamental conditions:

1) there must exist a sufficient endowment of fossil fuels with a sufficient energy return for the energy invested (EROEI) [2] in order to create the new renewable infrastructure

2) The amount of fossil fuels burned must not exceed the amount that would bring irreversible ecosystemic transformations in the form of pollution and greenhouse gases. In other words, the quantity of $\mathrm{CO}_{2}$ generated during the 
transition must not exceed the limit that would lead to a temperature increase of $2^{\circ} \mathrm{C}$ over the pre-industrial level.

3) Throughout the transition, we need to maintain a supply of energy to society sufficient to keep functioning its main structures worldwide, in particular the food supply and food transportation system. That should also take into account the probable continuing increase in the human population and urbanization [3] from now to the end of the century and the desire of poor nation to improve their living standards.

In the present paper, we'll summarize some previous results [4] related to the quantification of the challenge ahead and discuss how the concept of the "Sower's strategy" can be used to facilitate policies that could lead to the energy transition in the terms described above.

\section{THE CHALLENGE OF THE TRANSITION.}

The calculations that quantify the above conditions are reported elsewhere [3] and only the main results will be summarized here. Calculations were performed on the basis of the "Energy Return on Energy Invested" (EROEI) [2] of the various energy technologies available, both fossil and renewable. The EROEI is defined as the ratio of the useful energy (exergy) obtained by a given energy technology or plant over its lifetime and the energy necessary to build, maintain, and eventually dismantle the plant(s). Obviously, this is the crucial factor in this kind of quantification since it allows the calculation of how much energy is available from the existing infrastructure and how much of it must be invested in order to build the new one. Energy technologies with higher EROEI can scale up faster because a smaller amount of energy must be allocated to their construction, maintenance, and replacement for the same amount of net energy produced. Assuming no fundamental breakthroughs in the available energy technologies, the results of the model calculation indicate that it is possible to match the energy produced today by fossil fuels with an equivalent amount produced by renewable technology, within the constraints outlined in the previous section. That is, the transition to a fully renewable energy supply is possible, at least in principle and taking into account that renewables produce mainly electrical power, so that many sectors of society will have to adapt to a new form of energy. On the other hand, the model calculations indicate that the transition that will be possible only if society will be willing to allocate fundamentally larger amounts of energy to building the new infrastructure of renewable energy than those allocated today, at least a factor of 10 larger, probably more than that. The figure below, illustrated the main results of the model calculations [3].

There follows that the transition is not necessarily a technological problem. Better technologies can help, but it is, more than all a question of resource allocation and that, in turn, is a question of policy. How to push society to allocate substantial resources not just for immediate consumption but for a relatively long term future and for the benefit of all humankind. This is the basis idea of the "Sower's way" [1]

\section{THE SOWER'S WAY}

If we leave the choices on the allocation of the production of the energy to the market alone, we face the problem that market choices are usually made on the basis of short-term considerations and, in several cases, barriers to the development of new technologies created by obsolete policy decisions and by vested interests in the old technologies If that remains the rule, we risk to face climate change or fossil fuel depletion (or both things together) without having sufficient resources available to create a new energy system. If we continue along this path we will eat all our seed corn and we will be left without enough seed for the next harvest.

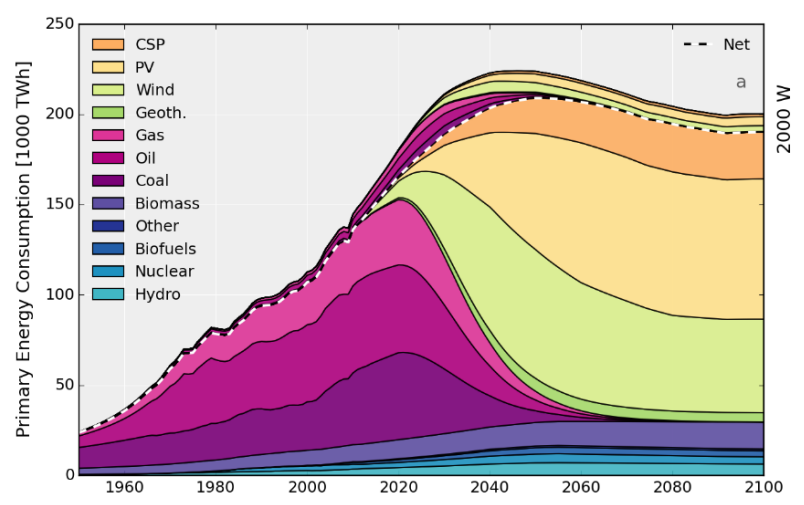

Figure 1. Primary energy supply evolution (in $\mathrm{PWh}$ ) for providing $2000 \mathrm{~W}$ average net power per capita by 2100 to a population of 10.8 billion. Fossil fuel emissions comply with a $990 \mathrm{Gt} \mathrm{CO}_{2}$ cap peaking in 2020 and phased-out by 2075 .

Unfortunately, the urgency of allocating resources for the transition is not perceived or poorly perceived by both the public and the decision makers. It is, in large part, a problem of communication. The public is bombarded by contradictory messages regarding climate change and the need to eliminating fossil fuels, in part also as the result of spin campaigns specifically designed to perpetuate the economic interests of the fossil fuels companies [5]. The result is that the public is confused and unable to recognize the correct information delivered to them [6]. We also see the results of a phenomenon that may be linked to the old saying that "a little knowledge is a dangerous thing." It has been observed that people with a higher than average degree of scientific knowledge may only use their knowledge tools in order to deny the existence or the urgency of the problem [7]

The question of effective communication on the climate change issue has been examined in several cases and in several forms, often finding that we face a conundrum: negative or "catastrophistic" messages tend to scare the public and to inhibit action [8]. But, if the true consequences of climate change are kept hidden or sweetened, the result seems to be simply apathy. In practice, we should try to avoid both mistakes: scaring the public or soothing the public doesn't work. Instead, it is often recognized that we must outline active and positive strategies to promote change [9].

The "Sower's Way" derives from the concept of encouraging positive action against the problems we face. It is rooted in the very old, and still well known, concept of "saving the seed." It can be found described, more or less explicitly, in some of the main religions of the world (e.g. in the Christian Gospels, Matthew, 13), but it is not in itself a religious concept. It is, simply, a practical concept: you must think to the future if you want to have a future. And that may involve making sacrifices. Supporting the "sower's strategy" suggest that people must make sacrifices during the transition, something that may not be considered as popular, but that is implicit in most of the current proposals for mitigating climate change. A "carbon tax", for instance, imposes some degree of sacrifice on the people who use fossil fuels. History shows that people are perfectly willing to make sacrifices for 
the public benefit, but the message that arrives to them must be clear and positive. In this sense, the recent papal encyclical on climate has been an excellent example of this positive approach that calls people to remember their responsibilities as human beings and inhabitants of planet earth.

Supposing that we can pass the message involved in the "Sower's way", the benefits for the earth's climate could be tangible. Implementing this strategy may not need formal measures; we can see it as a form wisdom that already exists in people's minds and that leads individuals and groups to supporting investments in renewable energy and in the correlated efficiency measures. Note that the Sower's way doesn't take fossil fuel interests as antagonists, but as potential allies. After all, energy production is the job of energy companies and the idea is that it is for their own benefit to invest in moving away from their current dependency on fossil fuels to a system based on renewable resources. The diffusion of this concept could also result in practical measures to ease permits and reduce bureaucracy for investments in sustainability.

Perhaps most importantly, the Sower's way is a quantitative approach to the transition, based on physical factors and not on the vagaries of the markets. As such, it can be presented to the public and to decision makers as a rational complementary guide for setting up policies not relying on belief in the possibility of infinite, unconstrained growth, or based on the often emotional and ideological approaches to the concept. Markets do have a fundamental role to play in the transition, but their capability of efficiently allocating resources for short term resources does not guarantee that the energy transition will be fast enough for the targets of avoiding the disruption of the ecosystem that is resulting from climate change.

In itself, the sower's strategy, formally or informally implemented, does not guarantee a smooth transition to a sustainable (and cool enough) world. It can't go against the laws of physics and it can't allow humankind to continue growing forever. Adapting our economy to renewable energy [10] requires new infrastructure, rethinking industrial processes and agricultural practice, adapting to the gradual reduction in the availability of all mineral resources. Among other things, we need to learn how to use renewable energy to power agriculture [11], to replace rare minerals with common ones (e.g. copper with aluminum), to manage waste as a resource and not as a burden, and much more. All this is possible, but not easy and it has a cost, In order to have a future, we need to make sacrifices. This is something that was clear to our ancestors and can be understood also by us, their descendants.

\section{CONCLUSIONS}

Building up a completely sustainable "circular" economy is a difficult task, but not an impossible one. The only impossible thing is to keep civilization alive without the availability of cheap energy and resources. The sower's strategy may give us a chance for guiding our policies for a society based on renewable energy, a step toward a completely circular society. No matter how implemented, the sower's strategy implies that we need to invest sufficient resources in the short term in order to create a new energy system before the depletion of fossil carbon or the negative effects of global warming makes it impossible to do so, but not so much that it would be an excessive burden on people's welfare. It is a window of opportunity that will not be there forever, but which still exists today. If we are willing to invest in the future, we can still have a future.

\section{ACKNOWLEDGMENT}

Ugo Bardi and Ilaria Perissi acknowledge the support of the MEDEAS project, funded by the European Union's Horizon 2020 research and innovation program under grant agreement No. 691287

\section{REFERENCES}

[1] U. Bardi, "The Sower's strategy: A way to speed up the energy transition," in Disrupting the Future: Great Ideas for Creating a Much Better World, W. Visser, Ed. London: Kaleidoscope Futures, pp. 15-19.

[2] C. A. Hall, C. J. Cleveland and R. Kaufmann, Energy and Resource Quality: The Ecology of the Economic Process, New York: Wiley Interscience, 1986.

[3] C. Delmastro, G. Mutani, L. Schranz and G. Vicentini, "The role of Urban form and socio-economic variables for extimating the building energy saving potential at the urban scale," International Journal of Heat and Technology, vol. 33, No.4, pp. 91-100, 2015. DOI: $10.18280 /$ ijht.330412.

[4] S. Sgouridis, U. Bardi and D. Csala, "The sower's way. Quantifying the narrowing net-energy pathways to a global energy transition," Environ. Res. Lett., vol 11 094009, 2016. DOI: $10.1088 / 1748-$ 9326/11/9/094009.

[5] N. Oreskes and E. M. Conway, Merchants of Doubt: How a Handful of Scientists Obscured the Truth on Issues from Tobacco Smoke to Global Warming, New York: Bloomsbury Publishing USA, 2010.

[6] W. R. L. Anderegg, J. W. Prall, J. Harold and S. H. Schneider, "Expert credibility in climate change.," Proc. Natl. Acad. Sci. U. S. A., vol. 107, no. 27, pp. 12107-9, Jul. 2010. DOI: 10.1073/pnas.1003187107.

[7] D. Kahan, E. Peters and M. Wittlin, "The polarizing impact of science literacy and numeracy on perceived climate change risks," Nat. Clim. Chang., vol. 2, pp. 732-735, 2012. DOI: $10.1038 /$ nclimate 1547.

[8] M. Hulme, "Newspaper scare headlines can be counter-productive," Nature, vol. 445, no. 7130, pp. 818-818, Feb. 2007. DOI: 10.1038/445818b.

[9] S. O'Neill and S. Nicholson-Cole, "'Fear won't do it': promoting positive engagement with climate change through visual and iconic representations," Sci. Commun., vol. 30, no. 3, pp. 355-379, Jan. 2009. DOI: $10.1177 / 1075547008329201$.

[10] A: Mirandola and E. Lorenzini, "Energy, environment and climate: From the past to the future", International Journal of Heat and Technology, vol. 34, no. 2, June 2016, pp. 159-164. DOI: 10.18280/ijht.340201.

[11] U. Bardi, T. El Asmar and A. Lavacchi, "Turning electricity into food: the role of renewable energy in the future of agriculture," J. Clean. Prod., vol. 53, no. 15, pp. 224-231, Apr. 2013; DOI: 10.1016/j.jclepro.2013.04.014. 